R e vi e w s 



\title{
Jussawalla, Feroza (2003): Chiffon Saris. Toronto: TSAR Publications, 92 pages.
}

\author{
Reviewed by Silvia Caporale Bizzini \\ University of Alicante, Spain
}

Feroza Jussawalla's Chiffon Saris is a precious gift. In this beautifully constructed collection of poems, the reader comes to know and understand, page after page, how Jussawalla writes herself and her world(s). While writing on life, illness and death, Jussawalla bravely declares in "The Life and Death of a Death Mask": "Surrounded by a tin halo, embellished with a/marital tili, my eyebrows affirmations, /I am that I am. Om bhur buh svaha/" (35; my emphasis). This not a quest for identity, it is a firm, intensely poetic and fiercely committed declaration of identity. The climax of her highly Romantic claim "I am a poet" ("Rainbow", 89), is the last in a book that transmits with great emotional strength the complex net of interlocking knots weaving Jussawalla's self-portrait. In her book Sexing the Self, a study on the relation between theory and practice in the definition of selves, Elspeth Probyn argues that by defining ourselves and our identities, "We can ... talk of an active voice, one that is actively implicated in and spoken out of gendered everyday practices and places" (1993: 87). This is exactly what Feroza Jussawalla accomplishes through her poems. The woman, the migrant, the writer, the theorist, the mother, the daughter, as well as her ordeals of infertility and cancer, are encapsulated in these four words, "I am a poet".

Words become the tools the poet uses to write her self as a diasporic subject that exists in-between languages, cultures, religions, traditions. In "Tierra de la Luna" she proudly claims: "Soy de la India, pero también de Nuevo México./Of India, but also of the soil of New Mexico,/ .../I've lived longer here, than there,/But I'm always asked, 'What are you?'/What AM I ? Can I say, 'I AM that I am?' " (10). In the opening poem, "Indian", English and Spanish intermingle and carry us from Jahilia to Medina to Chimayo, through colonial and postcolonial geographies, colours, expressions. In the last verses Jussawalla shows her concern and empathy with the displaced, regardless of homeland, concluding: "We are all the same, people/coming overland through the/northwestern passages into the

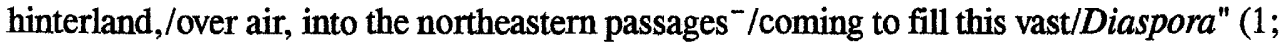
my emphasis). This is just the beginning of an intimate journey that shuttles the reader through shrouded, private spaces; poems like "Garas", "Indigent" or "Golden Girls" are representative of the metaphysical dimension as well as of the daily flux of life and the small events that make it worth living.

We as readers follow the poet's thoughts while she delves into her feelings and paints her everyday life. In the purest Wordsworthian style, Jusawalla moves from common details to a higher understanding of the meaning of life and death, remaining sociallycommitted. Her first person poetic writing develops through a time line that maintains a strong connection with nature without leaving history aside; for example, in "Terror", a poem on September 11, she voices her grief and rage: "Terror/strikes the heart/of those who speak out/after the attack/September 11, 2001./Terrorists/silenced us/here, in our adopted homelands..." (87). Senseless violence may silence the voiced subject and push her 
back to subalternity. But this is not what happens in Feroza Jussawalla's case, for she is unwilling to learn to live "in-between" the old carefully constructed, yet agonizing, society and the new explosion of emotions resulting from the terrorist attack. Her poetry and her cry against death amount to an answer to the question: Can the subaltern speak?

If we analyse the process of identity formation depicted in this collection from a Gramscian perspective, we can claim that the poet's autobiographical "I" takes shape by transmitting the reader the intimate process she has gone through in order to understand her own needs and fears and how important relations among individuals are in this process intimacy, to borrow his own words. I would argue that the poem "My Mother" is one of the most touching illustrations of the intimate relations that Jussawalla transforms into textuality. Being herself a mother and struggling with cancer, the poet can finally come to terms with past emotions and write: "But older and wiser/now/I give myself and her/a new lease on life./Forgiveness" (42). In this sense Chiffon Saris is the manifesto of a successful negotiation between the poet's own identity, the people that surround her and the places in which she lives. It is a powerful life statement, where words become a path to the selfawareness that gives the author the power to act on her own destiny.

Works cited

Probyn, Elspeth (1993): Sexing the Self. Gendered Positions in Cultural Studies. London: Routledge.

Fernández Álvarez; M. Pilar and Antón Teodoro Manrique (2002): Antología de la literatura nórdica antigua. Salamanca: Ediciones Universidad.

Reviewed by José R. Belda

University of Alicante, Spain

Few universities in Spain offer specialized courses on Old Scandinavian Languages and Literatures today. However, every scholar involved in Germanic Linguistics is aware of the historical relevance of Old Norse and the Sagas, which have played a vital role in the development of other Germanic languages, namely English. Although originally designed as a textbook, this elegantly edited anthology of Old Scandinavian texts can also serve as an excellent introduction to the history of Old Norse and Old Icelandic and to their respective literatures.

The book Antología de la literatura nórdica antigua can be clearly divided into three different sections: The first section (Chapter 0 ) offers a concise and clear-cut introduction to some literary and cultural aspects of Old Norse and Old Icelandic from a comparative European perspective. Here the authors comment on the origins of the early poetry and prose written in both languages along with their historical background. In the last part of this Introduction they also provide a coherent classification of the different Old Icelandic 
documents, which traditionally have been divided into two genres: Eddic and Skaldic verse with their several variants (fornyrdislag, málahattr, bölkr, etc) and their inherent characteristics (alliteration, helming, etc). The second section, chapter 1 , contains over two hundred pages of Old Norse and Old Icelandic texts with a parallel translation into Spanish, each text being preceded by a short historical and literary introduction. Finally, the third section (chapters 2, 3, 4 and 5) includes two dictionaries, the first one is actually an Old Norse and Old Icelandic-Spanish glossary while the second is a valuable dictionary of some proper terms used in the texts with their definition and a brief historical comment in Spanish. This section also contains a useful appendix summarizing the most important grammatical aspects of Old Norse and Old Icelandic such as tables with noun declensions and verbal conjugations. Finally, the authors supply a very detailed and descriptive bibliography including dictionaries, glossaries and general as well as specific studies about Old Scandinavian Literature.

Although many Spanish linguists, scholars and translators did previously research on the rich Old Scandinavian literature, outstandingly Francisco Uriz and Jose Antonio Fernández Romero through their translations, this book truly represents the first comprehensive work covering this field in Spanish with academic purposes and fills an important gap by providing students and teachers with useful material for the classes and for the in-depth study of Old Icelandic and Old Norse languages and literatures.

Schwarlz, Anja (2001). The (im)possibilities of machine translation. Peter Lang. Frankfurt am Main. 323 pages.

\section{Reviewed by Silvia Borrás Giner}

The (im)possibilities of machine translation is an introduction to the world of automated translation. The author presents in this work the essential theoretical characteristics of human and machine translation processes and she also evaluates the quality and output of several programmes from a comparative perspective. The first introductory chapter focuses on the existing degrees of automation and on the various machine translation generations that have been developed up to now. Schwarlz shows and comments on the evolution of these machines from the mechanical translation phase to the artificial intelligence stage, i.e. from the lexical substitution approach to the application of world knowledge into algorithmic based systems. The second section of the work deals with the two different processes representing machine and human translation, including a comparative analysis between both processes. As regards the machine translation process, various theories and models are suggested to know how direct, interlingua and transfer systems operate. Furthermore, the author illustrates the linguistic problems created by different types of ambiguity and explains the possible solution from a syntactic and semantic perspective. Concerning the human translation process, some hypotheses are considered so as to understand what happens in the translator brain when this process takes place. Although no 
decisive conclusions are given, think aloud protocols help Schwarlz to consider the psycholinguistic model as the most appropriate for the human translation process. As a result, the author maintains that the computer formal logic is not up to the same standard as the human natural one, because the former works retrospectively, that is, it lacks the flexibility to handle unexpected situations.

After comparing the processes of human and machine translation, the third chapter of the book is based on a more practical perspective. In order to assess the output of machine translation systems, three programmes (Langenscheidt T1 3.0, Globalink Power Translator Pro 6.0 and Pons Personal Translator Plus98) are thoroughly compared in accordance with several evaluation methods, namely, the four scale rating, the benchmark test, the backtranslation, the standardized error counting and the test suite. The first evaluation method, the four scale rating, grades the translated texts from perfectly intelligible to hopelessly unintelligible. The second one, the benchmark test, is used to indicate which grammatical features are covered or not by a machine translation system. The third method, backtranslation, undergoes a double translation process: the original text is first translated into the target language and then the translated output becomes the input for the second translation back into the source language. The fourth one, the standardized error counting, takes place at the post-editing stage and the last method, the test suite, is actually a secondary method which inevitably needs one of the aforementioned mechanisms to produce some comparable results. The author highly recommends that the evaluation of the different methods should be done by people not only bilingual but also familiar with the way a machine translation system works. The fourth chapter, entitled future perspectives, provides some guidelines for every machine translation specialist. In this section, special attention is paid to the research directions of computer science and mathematics. Here Schwarlz skips from the traditional approaches, namely the direct, interlingua and transfer systems, to new machine translation strategies based on artificial intelligence. As some specialists maintain, the current applications of expert systems, artificial intelligence, fuzzy logic, chaos theory and neural networks can expand and improve machine translation processes. According to the author, there is a lesson to be drawn from these recent research tendencies, because all new contributions might direct natural language processing in the long term. In the last part of the book Schwarlz provides some conclusions. Although it is the shortest chapter it perfectly reflects the essence and summarizes the most relevant ideas presented in all the previous sections. In short, machine translation could open up new important tasks for translators but it will never replace human translation, because at present human translation is more precise than machine translation. Nevertheless, the author foresees that experts systems, artificial intelligence, neural networks, fuzzy logic or chaos theory will advance machine translation results substantially. There is a final appendix at the end of this chapter.

This book is a very comprehensive introduction to the concepts and principles that characterize machine translation. Although it is divided into six chapters, it has basically two different parts: one theoretical and one more practical. In our view, this distribution makes the book easier to understand, because it first introduces the main standards of 
machine translation processes and then focuses on the pragmatic and real performance of three specific systems. Moreover, most of the sections include a little compilation or summary of the principal ideas that have been disclosed and an evaluation of all methods and results presented. The only difficulty in this work is that the examples of machine translated texts are carried out both in German and in English.

Terttu Nevalainen and Helena Raumolin-Brumberg (2003): Historical Sociolinguistics: Language Change in Tudor and Stuart England. Great Britain: Pearson Education, 260 pages.

\section{Reviewed by Sara Ponce Serrano}

Historical Sociolinguistics: Language Change in Tudor and Stuart England is a comprehensive study of language variation and change from a social perspective. In the preface the authors present the process of data compilation together with the material used for the analysis. The research is based on an electronic collection of personal letters (Corpus of Early English Correspondence 1410-1681), consisting of 6,000 letters and approximately 800 writers. Through this corpus Nevalainen and Raumolin-Brunb analyse some of the linguistic changes present in literate sections of the English population and, for this purpose, they focus on the Late Middle and Early Modern English periods, with special attention to the Tudor and Stuart times, from an interdisciplinary Sociolinguistic approach.

The work is divided into ten chapters, including three different appendices which contain the methodology used in the graphical representation of data, numerical information in relation to the different linguistic changes and the list of letters used in the study. Chapter one serves as an introduction, followed by eight chapters and a final chapter summarising the conclusions in relation to the analysis previously done. Chapter two deals specifically with the study of the different models through which the social context of the English language can be studied. Several sociolinguistic paradigms are here commented and the repercussions of the different models in language change are described. In chapter three, Nevalainen and Raumolin-Brunberg present the historical data used consisting of personal correspondence from 1410 to 1681 . The Tudor and Stuart England periods are the background for the reconstruction of the social contexts of language use. Chapter four is initially dedicated to the time courses of all linguistic changes analysed. In the second part of this chapter the authors provide the reader with different material related to several linguistic changes through the history of English. In the last part of this chapter fourteen grammatical changes previously analysed are illustrated and explained with several examples. In the four next chapters, six, seven, eight and nine, the authors relate these fourteen linguistic changes present in the history of the English language with several sociolinguistic factors: real and apparent time, gender, social status, regional and register variation and the role these issues played in language change. 
In order to help the reader understand the different linguistic changes in relation to the sociolinguistic factors considered, the authors illustrate these changes with several graphics, containing a detailed description of them and of their relation with frequency and time. In conclusion, this is a thorough work which can be very useful for both teachers and students interested in Historical Linguistics and Sociolinguistics. 